\title{
Infliximab treatment in a case of rheumatoid scleromalacia perforans
}

\author{
Trattamento con Infliximab \\ in un caso di scleromalacia perforante reumatoide
}

\author{
R. Herrera-Esparza, E. Avalos-Díaz \\ Department of Immunology. Centro de Biología Experimental, Guadalupe, Zacatecas, México
}

\begin{abstract}
RIASSUNTO
L'impegno oculare in corso di artrite reumatoide (AR) si manifesta con iperemia della congiuntiva e dell'episclera e, in casi particolarmente severi, l'episclerite può evolvere come sclerite nodulare e scleromalacia perforante. Viene presentato un caso di scleromalacia perforante in una donna di 56 anni con una storia di AR sieropositiva di classe funzionale IV della durata di 20 anni. Durante questo periodo la paziente ha ricevuto esclusivamente farmaci anti-infiammatori non steroidei. Ha sviluppato una episclerite acuta dell'occhio sinistro che è rapidamente evoluta in scleromalacia perforante. Dal momento che l'occhio sinistro si era perforato è stato enucleato chirurgicamente e la paziente è stata mantenuta in terapia steroidea. Ciononostante due mesi dopo ha sviluppato un nuovo esordio di episclerite dell'occhio destro seguito da scleromalacia. È stata quindi valutata per la prima volta da un Reumatologo e trattata con una dose mensile di 200 mg di infliximab per i seguenti 4 mesi. La terapia biologica è stata accompagnata da methotrexate e prednisone. Con questo trattamento la lesione oculare è migliorata drammaticamente e dopo 4 mesi è stata ottenuta la completa remissione dell'AR e della sclerite. In conclusione, i farmaci bloccanti il TNF sono trattamenti efficaci nelle complicazioni oculari dell'AR.
\end{abstract}

Reumatismo, 2009; 61(3):212-215

\section{INTRODUCTION}

$\mathrm{R}$ heumatoid disease can cause ocular inflammation of the conjunctiva, sclera, and uveal tract. The sclera is an avascular layer covered by the episclera that is highly vascularised and can be affected by inflammation. Frequently, ophthalmic involvement in rheumatoid arthritis (RA) and spondyloartrhophaties results of a systemic and chronic inflammation that can produce devastating effects. Clinically, episcleritis looks similar to conjunctivitis, although there is no discharge. A common symptom of episcleritis is redness, and patients may also complain of foreign body sensa-

Indirizzo per la corrispondenza:

Dr. Rafael Herrera-Esparza

Chepinque 306

Col. Lomas de la Soledad

Zacatecas,

98040 Zac México

E-mail: rafael.herrereraesparza@gmail.com tions, itching, burning sensations, photophobia, blurred or halo vision, and excessive tearing (1). The biochemical nature of these ophthalmic manifestations is related to the release of inflammation mediators, including tumour necrosis factor (TNF) and other inflammatory cytokines (2).

Episcleritis is an inflammation of the episcleral tissue between the conjunctiva and the sclera. Episcleritis is a complication that occurs in $30 \%$ of RA patients and takes place in the absence of infection (3). Frequently, it is associated with underlying, advanced, and destructive arthritis with extrarticular manifestations. Rheumatoid episcleritis produces necrotic areas with thinness that allows the exposure of the uvea, and scleromalacia perforans is a serious complication of RA.

Traditionally, scleritis has been treated with steroids and immunosuppressive agents. However, the availability of anti-TNF biological agents is changing the prognosis of acute rheumatoid ocular involvement (4). We report a clinical case of a woman living in 
a rural environment who had chronic and destructive RA. She was treated with NSAIDs yet she exhibited ocular involvement and her condition rapidly evolved into scleromalacia perforans. After the patient was treated with infliximab, a remarkable remission of the sclera inflammation was observed.

\section{CASE REPORT}

A 65-year-old female residing in a farming community whose clinical history did not disclose familial autoimmune background developed rheumatoid arthritis. The disease had an evolution of 15 years prior to ocular involvement. She was treated by a family physician with NSAIDs and low doses of prednisone, but she was never evaluated by an internist or rheumatologist. Four months before evaluation by a rheumatologist, she developed episcleritis, followed by scleromalacia perforans in the left eye. The ophthalmologist prescribed dexametasone therapy in bolus, followed by $50 \mathrm{mg}$ of prednisone daily. She did not respond to this therapy, and her scleromalacia rapidly evolved into eye perforation. For this reason, urgent eye enucleation surgery was performed. After surgery she was treated with 15 $\mathrm{mg}$ of prednisone per day, but in spite of steroidal therapy, she developed scleritis of remaining eye over the following two months. For this reason, the ophthalmologist referred her to a rheumatologist. At the first evaluation, she exhibited the progressive effects of her chronic disease. She was unable to walk and had contractures in her elbows, knees, and fingers, ulnar deviation of both hands, which were atrophic, and rheumatoid nodules in her elbows and ankles. As depicted in Figure 1, the right eye exhibited redness due to scleritis, and she complained of ocular pain, foreign body sensation, photophobia, blurred vision, and excessive tearing.

Clinical laboratory tests were positive for rheumatoid factor (600 U; normal $40 \mathrm{U}$ ), showed an accelerated erythrocyte sedimentation rate of 50 $\mathrm{mm} / \mathrm{h}$ (Westergreen), and detected thrombocytosis of 450,000 . She was treated with of $1 \mathrm{~g}$ of cylophosphamide and $1 \mathrm{~g}$ methylprednisolone in bolus, yet in the following two weeks the inflammation in the right eye persisted. Consequently, she was given an infusion of infliximab (200 $\mathrm{mg}$ in 1 hour). This biological agent was administrated monthly for the following four months and induced a dramatic change. An improvement was observed two weeks after the first infusion. The sclera and conjunctiva inflammation progressively cleared, and the foreign body sensation, itching, burning, and photophobia disappeared (Fig. 2). After four months, the infliximab therapy was stopped, and she was treated with $10 \mathrm{mg}$ of methotrexate per week. Follow up occurred every two months over the next two years. During that time, she remained in remission free of ocular manifestations and did not suffer any side effects from the biological therapy.

\section{DISCUSSION}

A clinical case of scleromalacia perforans in a female patient with RA is presented. The lack of a suitable treatment available in her rural environ-
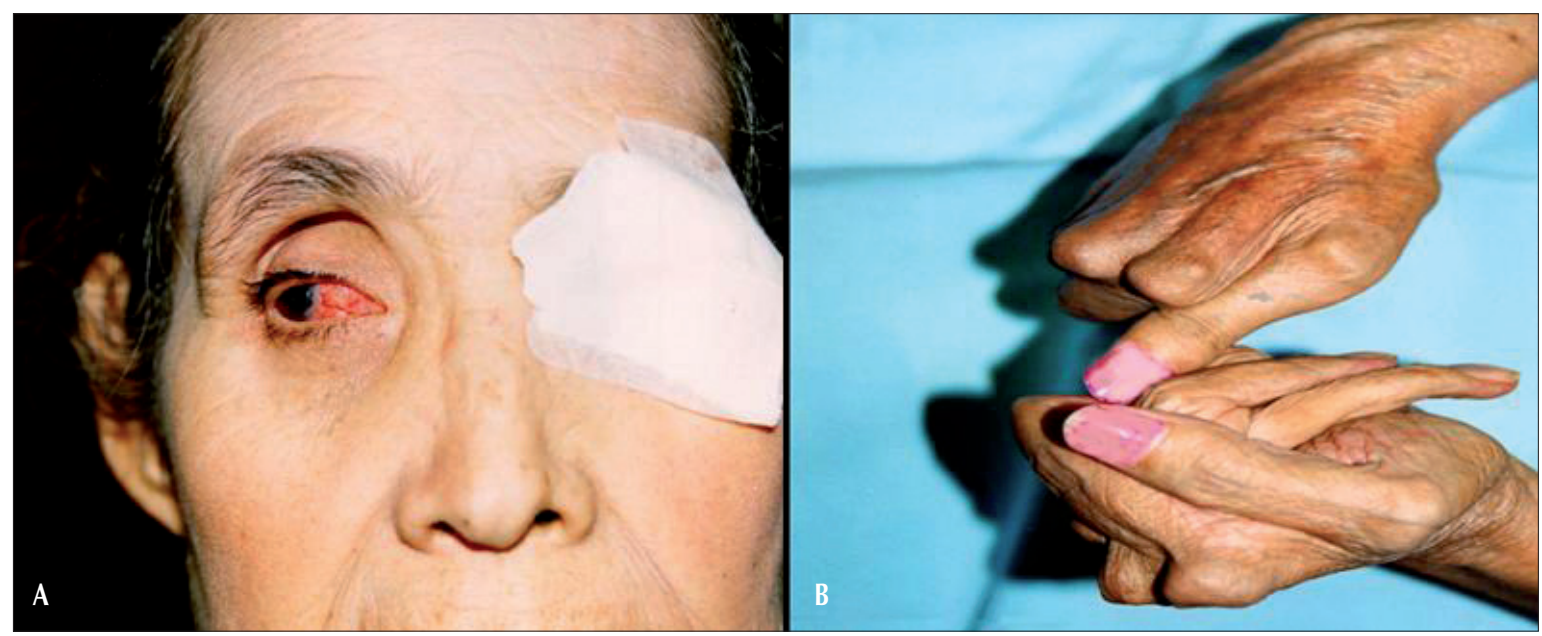

Figure 1 - A. The right eye exhibited redness due to scleritis, whereas on the left eye there was only a patch covering the empty ocular cavity. B. Both hands were atrophic and exhibited ulnar deviation, and fingers with flexion contractures can be seen. 


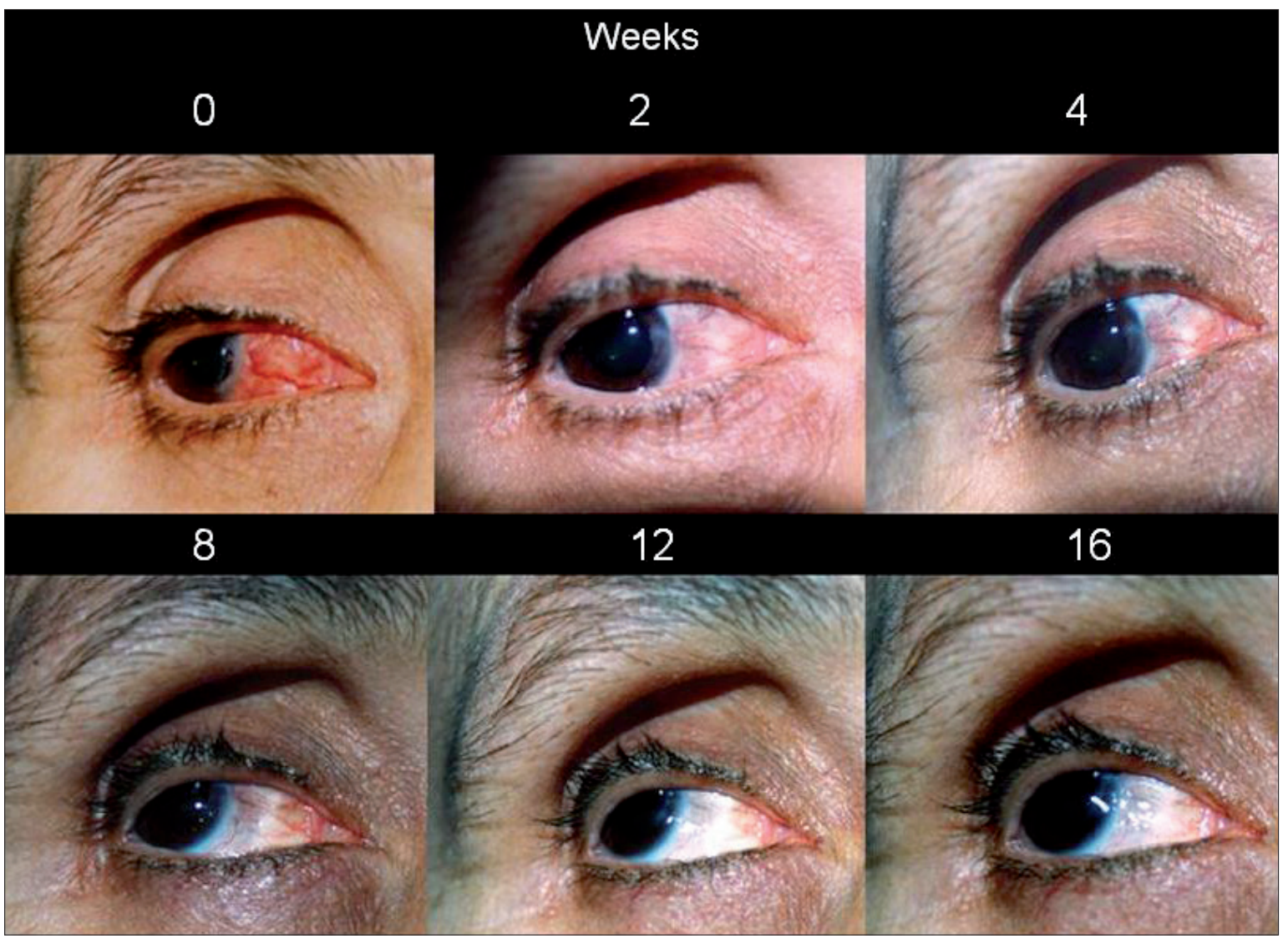

Figure 2 - The clinical evolution of the right eye from baseline to the 16th week of evolution under anti-TNF therapy.

ment resulted in a catastrophic evolution of the disease and the loss of her left eye. Two months after enucleation surgery, the patient developed acute and progressive scleritis of her unique eye, and anti-TNF infliximab was administered. Two weeks after the first dose, the ocular inflammation decreased, and dramatic results were archived over the following 16 weeks. Amazingly, the ocular lesions completely cleared (Fig. 1).

Anti-tumour necrosis factor alpha (anti-TNF-alpha) agents have been used in refractory inflammatory eye diseases associated with rheumatic diseases, especially in recalcitrant uveitis. The therapeutic advantages of anti-TNF agents include the rapid response and relief of symptoms, which decreases the need for topical steroids (5). A recent review that detailed the experiences of patients in clinical trials, as well as an uncontrolled case series treated with TNF antagonists, summarised the beneficial effects of biologicals in approximately 280 patients with various ocular conditions that were inadequately controlled by conventional therapies. This analysis demonstrates that TNF anta- gonists are useful in the treatment of ocular inflammation associated with rheumatoid arthritis, juvenile idiopathic arthritis-associated and chronic anterior uveitis, sarcoidosis, and Crohn's, Behçet's and Graves' disease (6). The present report describes a dramatic case of rheumatoid ocular involvement that caused the loss of the patient's left eye to scleromalacia perforans and involved acute scleritis of her unique eye. This process was very aggressive and had a rapid evolution, which put the patient at the risk of becoming blind. The decision to administer anti-TNF therapy was correct and critical to archiving excellent results in a relatively short period of time. Considering this case and the experiences of others, we can conclude that TNF blockers are effective therapeutic agents for ocular complications of rheumatoid arthritis.

\section{ACKNOWLEDGEMENTS}

Mr. Lepoldo Romero is especially thanked for his support in obtaining the infliximab therapy. This work was granted by PROMEP to UAZ-CA5 Autoinmunidad. 


\section{SUMMARY}

Ocular rheumatoid disease manifests as hyperemia of the conjunctiva and episclera, and in severe cases, episcleritis can result in nodular sclerotic and scleromalacia perforans. A clinical case of scleromalacia perforans in a 56-year-old woman with 20 years of seropositive rheumatoid arthritis of functional class IV is presented here. During that period, she received exclusively non-steroidal anti-inflammatory drugs (NSAIDs). She developed acute episcleritis of the left ocular globe, which rapidly progressed to scleromalacia perforans. Since the left eye became perforated, it was surgically enucleated, and the patient was maintained with steroidal therapy. Nevertheless, two months later she developed new-onset episcleritis of the right eye followed by scleromalacia. She was first evaluated by a rheumatologist and treated with $200 \mathrm{mg} /$ dose of infliximab, which was administered monthly for the following four months. The biological treatment was accompanied by methotrexate and prednisone. With this therapy, the ocular lesion dramatically improved, and complete remission of rheumatoid arthritis and scleritis was archived four months later. In conclusion, tumour necrosis factor (TNF) blockers are effective therapeutic agents in ocular complications of rheumatoid arthritis.

Parole chiave - Infliximab, rheumatoid scleromalacia, anti-TNF.

Key words - Infliximab, scleromalacia reumatoidi, anti-TNF.

\section{REFERENCES}

1. Patel SJ, Lundy DC. Ocular manifestations of autoimmune disease. Am Fam Physician 2002; 66: 991-8.

2. Harper SL, Foster CS. The ocular manifestations of rheumatoid disease. Int Ophthalmol Clin 1998; 38: 119.

3. Sainz De La Maz Serra M, Escobar Barranco JL, Foster CS. Characteristics of scleritis in patients older than 60 years. Arch Soc Esp Oftalmol 2001; 76: 425-30.

4. Diaz-Valle D, Miguelez Sanchez R, Fernandez Es- partero MC, Pascual Allen D. Treatment of refractory anterior diffuse scleritis with infliximab. Arch Soc Esp Oftalmol 2004; 79: 405-8.

5. Galor A, Perez VL, Hammel JP, Lowder CY. Differential effectiveness of etanercept and infliximab in the treatment of ocular inflammation. Ophthalmology 2006; 113: 2317-23.

6. Theodossiadis PG, Markomichelakis NN, Sfikakis PP. Tumor necrosis factor antagonists: preliminary evidence for an emerging approach in the treatment of ocular inflammation. Retina 2007; 27: 399-413. 